\title{
Investigating the Effect of Entrepreneurial Orientation on Hotel Performance: The Data Mining Capability Perspective
}

\author{
Obiageli Augusta Nwagwu \\ Department of Business Administration, Faculty of Management Science, Nile University of Nigeria, Abuja, Abuja, Nigeria \\ Email address: \\ obiagelinwagwu3@gmail.com \\ To cite this article: \\ Obiageli Augusta Nwagwu. Investigating the Effect of Entrepreneurial Orientation on Hotel Performance: The Data Mining Capability \\ Perspective. Science Journal of Business and Management. Vol. 9, No. 3, 2021, pp. 215-223. doi: 10.11648/j.sjbm.20210903.19
}

Received: July 22, 2021; Accepted: August 2, 2021; Published: August 7, 2021

\begin{abstract}
Today's businesses improve their performances through adoption of entrepreneurial orientation and leveraging their resources to create value for their customers and achieve competitive advantage. The aim of this study is to investigate the effect of entrepreneurial orientation on hotel business performance. Extant studies recognized moderating effect of third variables on how entrepreneurial orientation impacts performance. In this research, data mining capability is considered to be the moderating variable. With a population of 628 hotels in Abuja, data was collected via survey instruments administered on 250 hotel owners/managers and supervisors. The empirical study carried out in this research was achieved using questionnaires administered on hotel owners, supervisors and managers of three star hotels in Abuja, Federal Capital Territory, Nigeria. Out of the 250 distributed questionnaires, a total of 50 responses were received due to the fact that in most of the hotels, either the hotel owner or manager or supervisor alone gave their responses rather than a combination of any two. This figure therefore formed our final population size of 50 respondents. Regression analyses ware used to test the hypothesis on microsoft excel. Outcome of the study shows a significant moderating effect of data mining capability on the linkage between entrepreneurial orientation and performance. Findings also revealed that relationship between all other constructs is significantly positive with coefficients of determination value that reflect this positive relationship between constructs. It is recommended that future investigation into this field of study should give consideration to other geographical locations as well as other line of respondents to achieve more elaborate connection between entrepreneurial orientation and performance of hotel businesses in Nigeria. With a view to further boost support to this sector which is characterized with consistent uncertainties and environmental challenges, it is advised that regulators should put in place some palliatives to help enhance their business activities.
\end{abstract}

Keywords: Entrepreneurial Orientation, Performance, Data Mining Capability, Three Star Hotel, Regression Analysis

\section{Introduction}

Entrepreneurial orientation has recorded significant milestones in universal business trajectory [20] and has over the years remained a predominant concept in most ventures. For any business venture to succeed and be sustained, it will require constant exhibition and implementation of entrepreneurial skills and qualities. The hospitality industry is predominantly a service oriented one and consists of other subsets namely travel and tourism, accommodation, foods and beverages and entertainment [14] whose primary function is value creation to customers for growth, sustenance and survival of the business [37]. The implication of this is that they have to continuously create value for their customers in order to remain relevant, identify opportunities even in adverse situations and explore avenues to outdo competition [5]. Considering the delicate nature of this industry which has over the years recorded several adverse situations ranging from fierce competition, globalisation, environmental dynamism, uncertain business atmosphere and pandemics, the latest being covid 19 pandemic, it is pertinent for businesses in this sector to be more creative to build resilience and overcome unpredictable challenges which constantly pose threat in their business environment. It is a glaring fact that the hospitality industry was adversely affected by the novel covid 19 pandemic [46] following the lock down directive and shutting down of activities of the industry as a measure to curb spread of the disease. This was in addition to the shutting down of land borders, air space and sea borders which robbed the industry of their regular patronage and gave rise to a major 
strain on their business operations.

Hotels, being a subset of this industry witnessed a very grave downtime in their business activities as a fallout of the pandemic. Prior to the covid 19 pandemic, hotel occupancy in Nigeria shows that Nigeria's hotel industry accounted for $49.8 \%, 44.7 \%$, $43.6 \%, 42.4 \%$ and 42.6\%) occupancies in 2014, 2015, 2016, 2017, and 2018 respectively (Pricewaterhousecoopers, 2018). This position is a far cry from what was reported recently having recorded a major decline in occupancy level to its lowest of less than 5\% [25] indicating a tremendous fall. Report from the Nigerian stock exchange on the three major listed hotels presented a decline in revenue of almost 90\% [25]. Job losses occasioned by this development was about $60 \%$ of workforce as at November, 2020. Hospitality industry is noted to be labour intensive irrespective of the fact that technology has been incorporated in most aspects of the industry's business operations due to the volume and value of data generation. Hotels serve as networking centers [31] considering the fact that most local and international business travelers and tourists inevitably rely on hotel offerings. This strategically positions hotels as a viable business outfit that can support diversification of the economy. National Bureau of statistics Q1 2021 report shows accomodation sector contributed $1.01 \%$ of GDP indicating a year on year decline from $1.07 \%$ when compared to corresponding period of 2020. There is therefore urgent need to revamp this industry which has exhibited good potentials to support in economic growth.

The hospitality business is characterized by very high rate of unpredictability, uncertainties and turbulence. The current chanciness and highly competitive market hub exposes hospitality firms with numerous economic, financial and sociocultural challenges which affect their ability to give exceptional value to customers [14]. Hospitality is a major economic driver in most nations and involves myriads of services, facilities and attractions that create many entrepreneurial opportunities [48]. Nigeria is Africa's biggest market and records high influx of visitors which creates opportunity for hospitality business to thrive [29]. Recently, some scholars [44] stated that entrepreneurship and innovation are very key to shaping this universal industry and have prescribed for more studies. Based on findings of extant studies, the degree of relationship between entrepreneurial orientation and performance is complex and can vary, making it pertinent to evaluate the roles of other variables in this complex relationship [24]. Furthermore, entrepreneurs are affected by context as they are not commonly informed or have skills to respond in the same manner to competition in an economic rational way [19].

To tackle this complex connection between entrepreneurial orientation and performance, this study utilizes data mining capability as a moderating variable. In the current dispensation of business atmosphere, ability to gain competitive advantage is largely dependent on the ability to use data to understand customer trends and behavioral patterns [11]. Knowledge of data can be used as a forecasting tool [21], inventory management [16], logistics management [41] and supply chain management [30] who opined that data could be structured or unstructured and consists volume, variety, velocity and value. [30] posited that unstructured data from social media along with structured data could be used to develop a framework to explain supply chain resilience to checkmate unfavourable occurrences.

Data is a valuable resource which may elicit distinct creativity that is inimitable, enduring in value, and superior to other products [32]. Informed managers with effective understanding of their data can use it to achieve milestones for their organization, develop products and services to meet specific needs of customers based on identified patterns and trends [32]. Evaluations hinged on data is regarded as a way of arriving at effective management decisions [27]. Data mining capability is vital for interpreting complex information obtained from divers sources thereby reducing uncertainties regarding critical aspects of operations of firms. In modern business, data is an inseparable asset from business growth and sustenance as it helps organizations achieve efficiency [12], quality service rendition, and development of new products to meet expectations of customers $[13,8]$. This study's aim is to critically examine the influence of data mining capability and its degree of impact in moderating the link between entrepreneurial orientation and performance.

\subsection{Problem Statement}

Effect of globalization, change in technology landscape as well as heightened competition has brought about upgraded sophistication of customers in terms of taste and expectations. In order to meet high customer expectations, fierce global competition and a hasty changing technological landscape, organizations must raise their entrepreneurial profile if they want to survive $[6,36]$. The suddenness with which hotel business environment changes points to one fact "firms with high entrepreneurial knowledge have an edge over those without" [17]. This unpredictability was heightened with the recent outbreak of the covid 19 pandemic. Hospitality, being a major economic driver in most nations, creates many entrepreneurial opportunities [48]. Of recent, researchers have examined the connection between entrepreneurial orientation and firm performance by considering additional variables which can be internal or external factors. To the best of the researchers knowledge, extant studies on entrepreneurial orientation and performance focused more on manufacturing industries with insufficient attention to hotel sector [44].

Hotel business in Nigeria holds very promising potentials and should be accorded commensurate recognition in research to help revamp this industry [3]. So far in Nigeria, only three major hotels are listed on the Nigerian stock exchange (SEC website). Some hospitality scholars [44] stated that entrepreneurship and innovation are very key to shaping this universal industry and have prescribed for more studies.

It is with a view to address these identified gaps that the researcher embarked on this study to investigate the moderating role of data mining capability in establishing a connection between entrepreneurial orientation and hotel performance. 


\subsection{Research Objectives}

The overall objective of this study is to investigate the linkage between entrepreneurial orientation and hotel business performance when moderated by data mining capability.

The specific objectives are as follows:

i. To examine how managers' innovative attributes affect hotel business performance.

ii. To ascertain the degree of impact of managers; risktaking abilities on hotel business performance.

iii. To evaluate the influence of managers' pro-activeness on performance of hotel business.

\subsection{Research Questions}

i. What is the degree of impact of entrepreneurial orientation on the sales turnover of hotel business.

ii. Does entrepreneurial orientation have a positive effect on the expansion of hotel business.

iii. Does Data mining capability have a significant effect on the linkage between entrepreneurial orientation and performance of hotels.

\subsection{Research Hypothesis}

Ho1 There is no positive effect of entrepreneurial orientation on sales turnover of hotel business.

Ho2 There is no significant effect of entrepreneurial orientation on expansion of hotel business.

Ho3 There is no significant effect of data mining capability on the linkage between entrepreneurial orientation and performance of hotel business.

\section{Literature Review}

\subsection{Conceptual Framework}

In this section, the study's main variables are discussed in detail covering issues such as their definitions, types and importance to an organisation as well as a clear explanation on how they will be conceptualized in this study.

\subsubsection{Entrepreneurial Orientation}

This study adopts Miller's (1983) conceptualisation (innovativeness, risk-taking and pro-activeness of entrepreneurial orientation. $\mathrm{He}$ defined entrpreneurial orientation as an organisation's strategic posture reflecting proactiveness, risk-taking and innovativeness. Entrepreneurial orientation has benefited from several recent studies both in theoretical and empirical applications thereby creating room for a vast platform for knowledge acquisition on subject matter. Entrepreneurship is seen as dynamic process of vision, change and creation [9]. Ability of management of organisations to deploy entrepreneurial approach can be observed through their willingness to take calculated risks even when the outcome is not yet certain. Such process requires energy and passion to better position the firm for gaining competitive advantage.

\subsubsection{Performance}

The term performance has remained a source of challenge to most scholars that have delved into this field due to its complexity [15]. There are several indicators of performance measurement and are usually grouped under financial or non financial [35]. Efficiency of a firm could be on one part while market share could be another. This study adopts the [39] conceptualization i) sales turn over and ii) expansion to enable the researcher achieve a more realistic view regarding performance in the hotel industry.

Every organization has set goals and objectives in other to align resource allocation towards attainment of these goals. What this means therefore is that organizational goals differ therefore performance becomes relative among organizations [44].

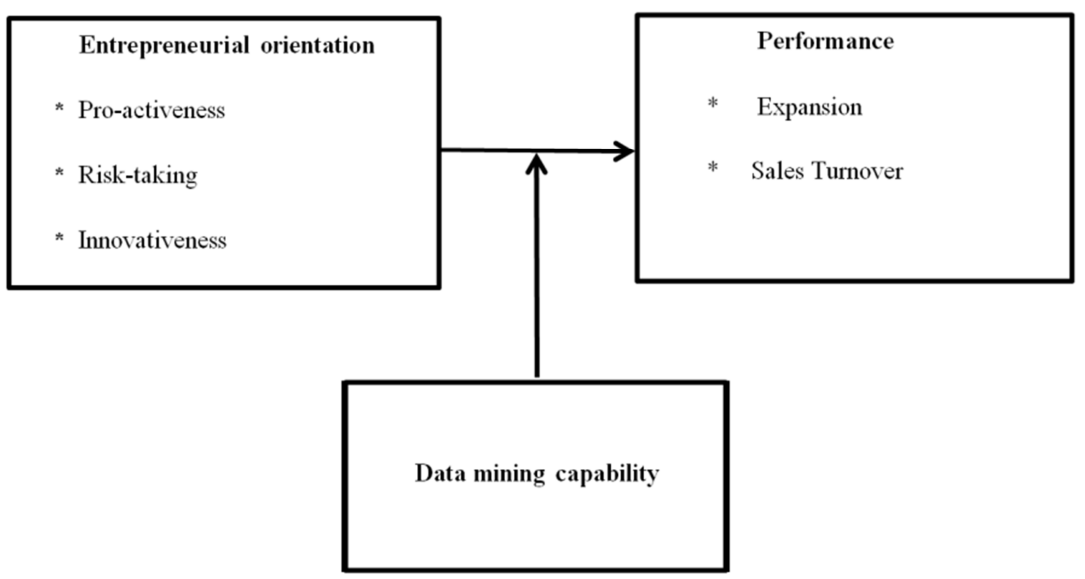

Figure 1. Study's Conceptual Framework (Researcher, 2021).

\subsection{Theoretical Review}

This section reviews various theories that have been utilized by prior studies that have investigated the linkage between entrepreneurial orientation and performance. The review of those extant studies revealed that eight different theories have been used as theoretical frameworks; however this study limits itself to three theories. 


\subsubsection{Resource Based Theory (RBT)}

Resource based theory was postulated in 1984 by a Danish economist and management theorist Birger Wernerfelt [43]. Resource based theory states that resources that are valuable, rare, hard to imitate and difficult to substitute best positions an organization for sustained growth [23].

Resource based theory makes two key assumptions 1) Every organization irrespective of size is a unique bundle of tangible and intangible assets, competences, capabilities and skills referred to as resource heterogeneity, 2) Some resources particularly intangible ones are difficult for rivals to imitate which is referred to as resource immobility [18].

Critics of Resource based theory point to the fact that 1) its applicability is too limited, 2) it has no managerial implications, 3) implies infinite regress, 4) Sustained competitive advantage is not achievable and 5) value of resource is too indeterminate to provide a useful theory [42].

\subsubsection{Dynamic Capability Theory (DCT)}

Dynamic capability was postulated by Teece et al., (1997) which is seen to be the extension of resource based theory to address firm's competitive advantage in extremely dynamic and volatile environment. Dynamic capability theory is defined as the ability of an organization to integrate, build and transform internal and external resources to confront rapidly changing business environment. Dynamic capability was conceptualized using three dimensions by [45] i) the sensing capability to identify, develop and scan out technological opportunities for meeting customer needs; ii) the seizing capability to mobilize needed resources to fulfil identified business opportunities and iii) the tranforming capability which accomodates all activities that reunites bundles of resources and capabilities. This capability creates room for alertness of the mind in identifying customer needs and business opportunities. Assumptions of this theory are: i) Every organisation is a unique bundle of tangible and intangible assets, competences, capabilities and skills refered to as resource heterogeneity, ii) Some resources particularly intangible ones are sticky which means difficult for rivals to imitate. This stickiness is referred to as resource immobility [40]. Some of the critiques of this theory say it is too difficult to measure empirically in trying to determine the relationship between dynamic capability and firm performance.

\subsubsection{Contingency Theory}

Contingency theory states that there is no best leadership style, a leader's effectiveness is dependent on the situation [1]. The framework says instead of organistions trying to change one's leadership style, they should rather match a particular leadership style to a particular situation. This suggests firms need to adapt in reaction to the conditions in which they exist. Contingency theory was postulated by Fred Fiedler, a leading Austrian psychologist in 1964 [26]. Different assumptions of this theory are: i) Different types of structures, processes and approaches are needed for different kinds of environment ii) Even in the same organisation, different approaches may be necessary to deal with different situations iii) Different variables including goals, values, and conditions of market determines the structure, process and overall approach of an organization iv) Management has to develop requisite diagnostic skill to achieve the right type of policy at the right time and right situation and v) Adaptability to change constitutes one of the biggest challenges to organizations therefore flexibility should be practised [12]. Critiques to this theory say it suffers inadequacy of literature as it did not spell out various types of actions to be taken under different situations. It is not enough to say managerial actions depend on the situation as the suggestion sounds simple but in practice it becomes complex because taking action involves analyses of a large number of variables with multifarious dimensions [48].

\subsection{Empirical Review}

In this section of the study, a review of extant studies that empirically tested the relationship between entrepreneurial orientation and performance were examined. Numerous authors considered entrepreneurial orientation as management stance in an organization as it provides relevant capability to improve the way firms make decisions [5]. The implication of this is that entrepreneurial orientation should emanate from top hierarchy since it involves allocation of resources for business pursuit. [38] investigated the impact of entrepreneurial orientation on performance across societal cultures and found a positive relationship even though the degree of relationship varied based on the national context. The research adopted a cross-sectional survey method among SMEs across seven national contexts. Data was analyzed using multi-level analyses and the result confirmed a positive relationship between entrepreneurial orientation and performance even though with varied degrees depending on whether it was a performance-based culture or socially supportive culture. The aim of the study was to establish that entrepreneurial orientation is a global phenomenom affected by environmental factors and cultures so that companies that are desirous of internationalising will be better informed. [47] applied the measurement model to further buttress this position in their research recognizing a mediating effect of market orientation. Secondary data was utilised for this research which was analysed using structural equation model to confirm a positive relationship between entrepreneurial orientation and organizational performance when moderated by market orientation. A cross-sectional survey research carried out by [4] on how entrepreneurial orientation influences performance recognized a two factor variable: mediating variable being environmental sustainability and moderating being stakeholder integration. Regression analyses was used in analysing data and the result indicates positive relationship exists between entrepreneurial orientation and organizational performance in the presence of the two factor variables. [10] also examined the linkage between entrepreneurial orientation and firm performance in the context of emerging market which was measured by absorptive capacity and boundary spanning. Data was collected via survey and analyzed using structural equation model. Findings revealed a positive relationship between entrepreneurial orientation and firm performance from the context of emerging market which was measured by 
absorptive capacity and boundary spanning. The impact of entrepreneurial relationship on firm performance was also investigated by [12] using big data analytics powered by artficial intelligence as the mediating variables and moderated by environmental dynamism. Data analysis was carried out using partial least squares - structural equation modelling which confirmed a positive result between entrepreneurial relationship and firm performance. This investigation posits that organizations that are entrepreneurial can make more informed decisions with their datasets for positive outcome.

\section{Methodology}

The study adopted a cross-sectional data which were gathered using a survey-based instrument to determine the relationship between entrepreneurial orientation and performance when moderated by data mining capability. There are 628 hotels in Abuja according to information obtained from the website: www.naijanews.com (2015).

Questionnaires were administered on hotel owners/managers and supervisors of 148 selected three-star rated hotels. A total of 250 questionnaires designed on a 5 point likert scale with anchors ranging from (1) strongly agree to (5) strongly disagree adopted from [47], were personally administered on hotel owners/managers and supervisors of these hotels with the assistance of a trained research assistant. 50 completed responses were returned representing $17 \%$ of questionnaires administered and used as the sample size. This was due to the fact that in most of the hotels, either the hotel owner or manager or supervisor alone gave their responses rather than a combination of any two. The questionnaires used consists of two parts: Part one is the bio data section while part two adopted a 5point likert scale to measure responses: 1 represents strongly agree while 5 represents strongly disagree. The collected data were analyzed using multiple linear regression.

The independent variable in this study, entrepreneurial

\begin{tabular}{ll}
\multicolumn{2}{l}{ SUMMARY OUTPUT } \\
\hline Regression Statistics \\
\hline Multiple R & 0.994776441 \\
R Square & 0.989580167 \\
Adjusted R Square & 0.986106889 \\
Standard Error & 0.965519424 \\
Observations & 5 \\
\hline
\end{tabular}

\begin{tabular}{llllll} 
ANOVA & \multicolumn{5}{l}{} \\
\hline & $d f$ & $S S$ & $M S$ & $F$ & Significance $F$ \\
\hline Regression & 1 & 265.6033167 & 265.6033167 & 284.9124736 & 0.000452838 \\
Residual & 3 & 2.796683276 & 0.932227759 & & \\
Total & 4 & 268.4 & & & \\
\hline
\end{tabular}

\begin{tabular}{lllllllll}
\hline & Coefficients & Standard Error & $t$ Stat & $P$-value & Lower 95\% & Upper 95\% & Lower 95.0\% & Upper 95.0\% \\
\hline Intercept & 2.809872314 & 0.606545583 & 4.632582268 & 0.018947681 & 0.879573563 & 4.740171065 & 0.879573563 & 4.740171065 \\
$\mathrm{X}$ Variable 1 & 0.719012769 & 0.042597182 & 16.87935051 & 0.000452838 & 0.583449524 & 0.854576014 & 0.583449524 & 0.854576014 \\
\hline
\end{tabular}

Figure 2. Relationship between entrepreneurial orientation and sales turnover in hotel business. orientation was adopted from Miller (1983) and adopted three dimension approach to a firm's entrepreneurial orientation. This approach indicates that a business entity is considered to be entrepreneurial when it exhibits proactiveness, risk-taking and innovative behaviours. The dependent variable, performance was measured using 2 non financial indicators i) expansion and ii) sales turnover adopted from [20], due to the difficulty in obtaining objective accounting information. The moderating variable, data mining capability was measured using a five item ranging from strongly disagree (1) to strongly agree (1) [12].

\section{Data Analyses}

This study's data were analyzed using regression analysis on micro soft excel to establish the relationship between the variables based on the hypotheses of the research. This study analyzes how entrepreneurial orientation influences outcome when moderated by data mining capability. Results of the relationship between measurements of entrepreneurial orientation and performance when moderated by data mining capability in the context of hotels performance shows a positive outcome. This means that the presence of data mining capability in the relationship between entrepreneurial orientation and performance reflects positive results.

The 3 null hypothesis were tested using the results obtained from the regression tool pack. The hypothesis were tested using the $\mathrm{P}$ value from the regression model which is set against significance value of 0.05 . If the $P$ value is less than 0.05 , the null hypothesis is rejected which means that the effect of the independent variable on the dependent variable is positive but if otherwise is the case, then the null hypothesis is accepted meaning the effect of the independent variable on the dependent variable is not significant.

Ho1: There is no significant effect of entrepreneurial orientation on sales turnover of hotel business. 
From the above figure, the $\mathrm{P}$ value is 0.000452838 which is far below the 0.05 significance level. The null hypothesis is therefore rejected thus the conclusion that there is a statistical confirmation of a significant relationship between dimensions of entrepreneurial orientation and sales turnover in hotel business. The R-square is 0.989580167 which is very strong as it indicates that $98 \%$ change in hotel business performance is predicted by entrepreneurial attributes affected by data mining capability.

Ho2: There is no significant influence of entrepreneurial orientation on the expansion of hotel business.

\begin{tabular}{ll}
\multicolumn{2}{l}{ SUMMARY OUTPUT } \\
\hline Regression Statistics \\
\hline Multiple R & 0.976288085 \\
R Square & 0.953138425 \\
Adjusted R Square & 0.9375179 \\
Standard Error & 2.047571471 \\
Observations & 5 \\
\hline
\end{tabular}

\begin{tabular}{|c|c|c|c|c|c|c|c|c|}
\hline & $d f$ & $S S$ & $M S$ & $F$ & Significance $F$ & & & \\
\hline Regression & 1 & 255.8223532 & 255.8223532 & 61.01833453 & 0.004367501 & & & \\
\hline Residual & 3 & 12.57764679 & 4.192548931 & & & & & \\
\hline \multirow[t]{2}{*}{ Total } & 4 & 268.4 & & & & & & \\
\hline & Coefficients & Standard Error & $t$ Stat & $P$-value & Lower $95 \%$ & Upper $95 \%$ & Lower $95.0 \%$ & Upper $95.0 \%$ \\
\hline Intercept & 3.985179319 & 1.196417426 & 3.330927176 & 0.044688315 & 0.177645101 & 7.792713537 & 0.177645101 & 7.792713537 \\
\hline $\mathrm{X}$ Variable 1 & 0.601482068 & 0.077000316 & 7.811423336 & 0.004367501 & 0.356432696 & 0.84653144 & 0.356432696 & 0.84653144 \\
\hline
\end{tabular}

Figure 3. Relationship between entrepreneurial orientation and hotel business expansion.

From the above figure, the $\mathrm{P}$ value is 0.004367501 which is also far below the 0.05 significance level. This means that the null hypothesis is rejected and therefore confirms that there is statistical significant relationship between different dimensions of entrepreneurial orientation and hotel business expansion. The R-square indicates 0.953138425 which is equally good as this shows that $95 \%$ change in hotel business performance is predicted by influence of data mining capability on the different dimensions of entrepreneurial orientation.

Ho3 There is no significant effect of data mining capability on the linkage between entrepreneurial orientation and performance of hotel business.

SUMMARY OUTPUT

\begin{tabular}{ll}
\hline \multicolumn{2}{l}{ Regression Statistics } \\
\hline Multiple R & 0.997076 \\
R Square & 0.994161 \\
Adjusted R Square & 0.992215 \\
Standard Error & 0.722773 \\
Observations & 5 \\
\hline
\end{tabular}

ANOVA

\begin{tabular}{llllll}
\hline & $d f$ & $S S$ & $M S$ & $F$ & Significance $F$ \\
\hline Regression & 1 & 266.8328 & 266.8328 & 510.7815 & 0.00019 \\
Residual & 3 & 1.567203 & 0.522401 & & \\
Total & 4 & 268.4 & & & \\
\hline
\end{tabular}

\begin{tabular}{lllllllll}
\hline & Coefficients & Standard Error & $t$ Stat & $P$-value & Lower 95\% & Upper 95\% & Lower 95.0\% & Upper 95.0\% \\
\hline Intercept & 2.86238 & 0.451908 & 6.333989 & 0.007958 & 1.424207 & 4.300552 & 1.424207 & 4.300552 \\
$\mathrm{X}$ Variable 1 & 0.713762 & 0.031582 & 22.60047 & 0.00019 & 0.613255 & 0.814269 & 0.613255 & 0.814269 \\
\hline
\end{tabular}

Figure 4. Data mining capability on the link between entrepreneurial orientation and performance. 
From the above figure, the $\mathrm{P}$ value is 0.00019 which is also far below the 0.05 significance level. This means that the null hypothesis is rejected and therefore confirms that there is statistical significant relationship between different dimensions of entrepreneurial orientation and hotel business performance when influenced by data mining capability. The R-square indicates 0.994161 which is equally good as this shows that $99 \%$ change in hotel business performance is predicted by influence of data mining capability on the different dimensions of entrepreneurial orientation.

\section{Discussion}

This section analyses the research questions.

RQ1. What is the degree of impact of entrepreneurial orientation on the sales turnover of hotel business.

Findings of this investigation as illustrated in Figure 1 showed that entrepreneurial orientation has a significant impact on volume of sales turnover of three-star rated hotels [28]. Prior studies have looked at moderating effect of market orientation in the connection between entrepreneurial orientation and hotel performance [47]. The findings revealed that entrepreneurial orientation alone is not suffiently enough to determine a strong relationship but is strengthened in the presence of market orientation to arrive at a significant impact on hotel business performance.

RQ2 Does entrepreneurial orientation have a positive effect on the expansion of hotel business.

In this section, outcome of our result as illustrated by figure 3 shows that entrepreneurial orientation influences expansion of hotel business. This finding is consistent with past study [20]. Entrepreneurial orientation supports and impacts business expansion [7].

RQ3 Does Data mining capability have a significant effect on the linkage between entrepreneurial orientation and performance of hotels.

The results as shown in Figure 3 indicates a significantly positive relationship on the moderating role of data mining capability on the relationship between entrepreneurial orientation and performance. This underscores the fact that knowledge of data empowers management of organisations in directing their business activities and allocation of resources towards attainment of goals [13].

\section{Conclusion}

The outcome of this study shows that activities of hotels that are entrepreneurial record more positive results than those seen to be conservative in their business approach. Entrepreneurial orientation affects the data mining capability of hotel managers, creating an atmosphere of better understanding of customer trends and traits thereby enhancing service delivery which ultimately leads to improved performance. It is therefore concluded that data mining capability of hotel business management positively moderates the relationship between entrepreneurial orientation and performance.

\section{Recommendation}

The findings of this study is recommended to policy makers in the guise of government regulatory agencies to put in place safety nets for hospitality industry considering the delicate and dynamic business environment they operate in. This could include but not limited to tax relief policy.

For hotel business owners and managers in Nigeria, it is advisable to develop and build entrepreneurial capabilities that can better position the hotel business in Nigeria to surmount vagaries of challenges that characterize the industry.

Lastly, this study will be a useful guide to hospitality scholars who should strive to ensure further research are solution oriented to support this promising industry by considering using customers as respondents as well as delving into other geographical locations.

\section{References}

[1] Abdulsallam, D. (2019). When to "Make" and When to "Buy": A Contingency Theory of Making Versus Buying Managerial Human Capital.

[2] Acar, E., Rasmussen, M. A., Savorani, F., Næs, T., \& Bro, R. (2013). Understanding data fusion within the framework of coupled matrix and tensor factorizations. Chemometrics and Intelligent Laboratory Systems, 129, 53-63.

[3] Adeiza, A. (2017). Factors influencing franchisees' business performance: A study on the Nigerian franchise system. Unpublished PhD Thesis. Universiti Utara Malaysia.

[4] Amankwah-Amoah, J., Danso, A., \& Adomako, S. (2019). Entrepreneurial orientation, environmental sustainability and new venture performance: Does stakeholder integration matter?. Business Strategy and the Environment, 28 (1), 7987.

[5] Arunachalam, S., Ramaswami, S. N., Herrmann, P., \& Walker, D. (2018). Innovation pathway to profitability: The role of entrepreneurial orientation and marketing capabilities. Journal of the Academy of Marketing Science, 46 (4), 744-766.

[6] Chavez, R., Yu, W., Jacobs, M. A., \& Feng, M. (2017). Manufacturing capability and organizational performance: The role of entrepreneurial orientation. International Journal of Production Economics, 184, 33-46.

[7] Chen, Y. C., Lin, Y. H., \& Tsai, H. T. (2020). Toward greater understanding of the relationship between entrepreneurial orientation and international performance. Management International Review, 60 (2), 211-245.

[8] Choi, T. M., Wallace, S. W., \& Wang, Y. (2018). Big data analytics in operations management. Production and Operations Management, 27 (10), 1868-1883.

[9] Chowdhury, F., \& Audretsch, D. B. (2021). A dynamic relationship between entrepreneurial orientation and entrepreneurial activity. Journal of International Entrepreneurship, 1-18. 
[10] Cui, L., Fan, D., Guo, F., \& Fan, Y. (2018). Explicating the relationship of entrepreneurial orientation and firm performance: Underlying mechanisms in the context of an emerging market. Industrial Marketing Management, 71, 27-40.

[11] Duan, Y., Edwards, J. S., \& Dwivedi, Y. K. (2019). Artificial intelligence for decision making in the era of Big Dataevolution, challenges and research agenda. International Journal of Information Management, 48, 63-71.

[12] Dubey, R., Gunasekaran, A., Childe, S. J., Bryde, D. J., Giannakis, M., Foropon, C.,... \& Hazen, B. T. (2020). Big data analytics and artificial intelligence pathway to operational performance under the effects of entrepreneurial orientation and environmental dynamism: A study of manufacturing organisations. International Journal of Production Economics, 226,107599 .

[13] Giannakis, M., \& Louis, M. (2016). A multi-agent based system with big data processing for enhanced supply chain agility. Journal of Enterprise Information Management.

[14] Gukushu, M. C. (2018). A critical assessment of innovation as a determinant of tourism competitiveness (Doctoral dissertation, North-West University).

[15] Gupta, V. K., Niranjan, S., \& Markin, E. (2019). Entrepreneurial orientation and firm performance: the mediating role of generative and acquisitive learning through customer relationships. Review of Managerial Science, 1-25.

[16] Huang, T., \& Van Mieghem, J. A. (2014). Clickstream data and inventory management: Model and empirical analysis. Production and Operations Management, 23 (3), 333-347.

[17] Ishaq, R., \& Attar, M. A. (2019). To explore the impact of knowledge hiding towards entrepreneurial intentions-An empirical study of software industry. Kuwait Chapter of the Arabian Journal of Business and Management Review, 8 (4), $1-13$.

[18] Khan, W. A., Hassan, R. A., Arshad, M. Z., Arshad, M. A., Kashif, U., Aslam, F., \& Wafa, S. A. (2020). The effect of entrepreneurial orientation and organisational culture on firm performance: The mediating role of innovation. International Journal of Innovation, Creativity and Change, 13 (3), 652-677.

[19] Kovaleva, S., \& de Vries, N. (2016). Competitive strategies, perceived competition and firm performance of micro firms: The case of Trento. In Contemporary entrepreneurship (pp. 75-93). Springer, Cham.

[20] Laskovaia, A., Marino, L., Shirokova, G., \& Wales, W. (2019). Expect the unexpected: examining the shaping role of entrepreneurial orientation on causal and effectual decisionmaking logic during economic crisis. Entrepreneurship \& Regional Development, 31 (5-6), 456-475.

[21] Liu, X., Singh, P. V., \& Srinivasan, K. (2016). A structured analysis of unstructured big data by leveraging cloud computing. Marketing Science, 35 (3), 363-388.

[22] Merendino, A., Dibb, S., Meadows, M., Quinn, L., Wilson, D., Simkin, L., \& Canhoto, A. (2018). Big data, big decisions: The impact of big data on board level decision-making. Journal of Business Research, 93, 67-78.

[23] Mitrega, M., Siemieniako, D., Makkonen, H., Kubacki, K., \& Bresciani, S. (2021). Versatile capabilities for growth in the context of transforming countries: Evidence from Polish manufacturing companies. Journal of Business Research, 134,
156-170.

[24] Muchiri, M., \& McMurray, A. (2015). Entrepreneurial orientation within small firms: A critical review of why leadership and contextual factors matter. Small Enterprise Research, 22 (1), 17-31.

[25] Nairametrics. 2020. Hotels in Nigeria are on the verge of collapse Nairametrics. http://nairametrics.com/2020/09/24/hotels-in-nigeria-are-onthe-verge-of-collapse.

[26] Namubiru, G., Onen, D., \& Oonyu, J. (2017). University Leadership during Times of Significant Transformation: A Case of Kyambogo University in Uganda. Journal of Education and Practice, 8 (10), 78-85.

[27] Njoroge, S. M., \& Maina, S. M. (2021). Entrepreneurial Orientation and Organizational Performance of Airlines in Kenya. Entrepreneurial Orientation and Organizational Performance of Airlines in Kenya, 73 (1), 13-13.

[28] Owusu, D., Mensah, I. K., Amenumey, E. K., \& Dei Mensah, R. (2019). Effect of Strategic Orientation on Performance of Star-Rated Hotels in Ghana. Journal of Business and Enterprise Development (JOBED), 8, 143-176.

[29] Otache, I., Edopkolor, J. E., \& Okolie, U. C. (2021). Entrepreneurial self-confidence, perceived desirability and feasibility of hospitality business and entrepreneurial intentions of hospitality management technology students. The International Journal of Management Education, 19 (2), 100507.

[30] Papadopoulos, T., Gunasekaran, A., Dubey, R., Altay, N., Childe, S. J., \& Fosso-Wamba, S. (2017). The role of Big Data in explaining disaster resilience in supply chains for sustainability. Journal of Cleaner Production, 142, 1108-1118.

[31] Peters, M., \& Kallmuenzer, A. (2018). Entrepreneurial orientation in family firms: The case of the hospitality industry. Current Issues in Tourism, 21 (1), 21-40.

[32] Poudel, K. P., Carter, R., \& Lonial, S. (2019). The impact of entrepreneurial orientation, technological capability, and consumer attitude on firm performance: A multi-theory perspective. Journal of Small Business Management, 57, 268-295.

[33] Pricewaterhousecooppers, 2018: UK hotels forecast 2018: As good as it gets?- Hospitality Net. http://www.hospitalitynet.org/performance.

[34] Pulka, B. M., Ramli, A., \& Mohamad, A. (2021). Entrepreneurial competencies, entrepreneurial orientation, entrepreneurial network, government business support and SMEs performance. The moderating role of the external environment. Journal of Small Business and Enterprise Development.

[35] Putra, I. A., Rofiaty, R., \& Djumahir, D. (2020). Investigating The Influence Of Entrepreneurial Orientation And Transformational Leadership On Organisational Performance With The Mediation Of Innovation: Evidences From A StateOwned Electricity Company In Indonesia. International Journal of Innovation Management, 24 (07), 2050085.

[36] Sahi, G. K., Gupta, M. C., Cheng, T. C. E., \& Lonial, S. C. (2019). Relating entrepreneurial orientation with operational responsiveness. International Journal of Operations \& Production Management. 39 (5), 739-766. 
[37] Savitri, E., DP, E., \& Syahza, A. (2021). Can innovation mediate the effect of adaptability, entrepreneurial orientation on business performance?. Management Science Letters, 11 (8), 2301-2312.

[38] Semrau, T., Ambos, T., \& Kraus, S. (2016). Entrepreneurial orientation and SME performance across societal cultures: An international study. Journal of Business Research, 69 (5), 1928-1932.

[39] Shah, S. Z. A., \& Ahmad, M. (2019). Entrepreneurial orientation and performance of small and medium-sized enterprises: Mediating effects of differentiation strategy. Competitiveness Review: An International Business Journal.

[40] Shan, S., Luo, Y., Zhou, Y., \& Wei, Y. (2019). Big data analysis adaptation and enterprises' competitive advantages: the perspective of dynamic capability and resource-based theories. Technology Analysis \& Strategic Management, 31 (4), 406-420.

[41] Shang, Y., Dunson, D., \& Song, J. S. (2017). Exploiting big data in logistics risk assessment via bayesian nonparametrics. Operations Research, 65 (6), 1574-1588.

[42] Schilke, O., Hu, S., \& Helfat, C. E. (2018). Quo vadis, dynamic capabilities? A content-analytic review of the current state of knowledge and recommendations for future research. Academy of management annals, 12 (1), 390-439.
[43] Tabares, A., Alvarez, C., \& Urbano, D. (2015). Born globals from the resource-based theory: A case study in Colombia. Journal of technology management \& innovation, 10 (2), 155165.

[44] Taheri, B., Bititci, U., Gannon, M. J., \& Cordina, R. (2019). Investigating the influence of performance measurement on learning, entrepreneurial orientation and performance in turbulent markets. International Journal of Contemporary Hospitality Management.

[45] Teece, D. J. (2014). A dynamic capabilities-based entrepreneurial theory of the multinational enterprise. Journal of international business studies, 45 (1), 8-37.

[46] Umadia, K. (2020). Exploring the Strategies for Sustaining Small-to Medium-Scale Enterprises (Doctoral dissertation, Walden University).

[47] Vega-Vázquez, M., Cossío-Silva, F. J., \& Revilla-Camacho, M. Á. (2016). Entrepreneurial orientation-hotel performance: Has market orientation anything to say?. Journal of Business Research, 69 (11), 5089-5094.

[48] Wang, S., Hung, K., \& Huang, W. J. (2019). Motivations for entrepreneurship in the tourism and hospitality sector: A social cognitive theory perspective. International Journal of Hospitality Management, 78, 78-88. 